\title{
Presynaptic Calcium and Serotonin-mediated Enhancement of Transmitter Release at Crayfish Neuromuscular Junction
}

\author{
K. Delaney, ${ }^{1,2,3}$ D. W. Tank, ${ }^{1}$ and R. S. Zucker ${ }^{3}$ \\ 'Department of Biophysics, AT\&T Bell Laboratories, Murray Hill, New Jersey 07974, 2Department of Physiology and \\ Biophysics, New York University, New York, New York 10016, and ${ }^{3}$ Department of Molecular and Cell Biology, \\ University of California, Berkeley, California 94720
}

Fura-2 microfluorometric measurements of calcium concentrations in excitor motor nerve terminals of the first walking leg of crayfish Procambrus clarkii were made during application of serotonin (5-HT) to examine whether changes in residual calcium concentration or calcium influx are responsible for the 5-HT-induced increase in transmitter release at this synapse. Calcium concentrations and EPSPs were monitored simultaneously during $0.5-\mathrm{Hz}$ and moderate-frequency (3-16 Hz) stimulation before, during, and after a 5-min application of 5-HT at concentrations between 5 and $100 \mu \mathrm{M}$.

We did not observe a significant increase in resting calcium concentration $\left[\mathrm{Ca}^{2+}\right]_{i}$ in presynaptic terminals during or after application of 5-HT despite simultaneously recorded excitatory junction potential (EJP) enhancement. Injection of the calcium buffer EGTA to concentrations sufficient to reduce significantly the buildup of frequency-dependent facilitation during trains of action potentials did not reduce 5-HT-mediated EJP enhancement. We therefore conclude that 5-HT does not release calcium from intracellular stores to an extent sufficient to overcome calcium buffering and removal systems. Spontaneous release of transmitter quanta was increased by $5-\mathrm{HT}$ to the same extent in normal and increased-osmolarity saline in the absence of measured changes in $\left[\mathrm{Ca}^{2+}\right]_{i}$. Thus, changes in residual calcium cannot explain 5-HT-induced synaptic enhancement.

Increasing the action-potential-mediated calcium influx by broadening the spike or by increasing extracellular calcium increased evoked transmitter release and increased the accumulation of calcium during trains of action potentials. However, though 5-HT produced a comparable synaptic enhancement, we found no evidence for increased calcium accumulation during trains of action potentials, suggesting that net calcium influx, buffering, and removal are not affected by 5-HT. Therefore, we conclude that 5-HT's action does not result from effects on calcium metabolism and suggest that it acts on the neurosecretory apparatus to increase the effectiveness of calcium for stimulating release. Furthermore, based on its relatively constant effects on facilitated and unfacilitated action-potential-evoked release and

Received Nov. 16, 1990; revised Mar. 4, 1991; accepted Mar. 11, 1991.

We wish to thank R. Y. Tsien for help in assembling the ratiometric imaging system at University of California at Berkelcy. This rescarch was supported by NIH Research Grant NS 15114 to R.S.Z. and by AT\&T Bell Laboratories. K.D. was the recipient of a Medical Research Council of Canada fellowship.

Correspondence should be addressed to Kerry Delaney, Room 1C-436, AT\&T Bell Labs, 600 Mountain Avenue, Murray Hill, NJ 07974.

Copyright (C) 1991 Society for Neuroscience $0270-6474 / 91 / 112631-13 \$ 03.00 / 0$ spontaneous transmitter release, we conclude that 5-HT actions are independent of the concentration of calcium that is driving release.

Serotonin (5-hydroxytryptamine; 5 -HT) is one of several neuroactive substances that modulate the release of neurotransmitters from nerve terminals (Kaczmarek and Levitan, 1987). Enhancement of synaptic transmission at the excitatory synapses of the claw opener muscle of lobster and crayfish by 5-HT has been studied extensively (Dudel, 1965, 1988; Glusman and Kravitz, 1982; Fischer and Florey, 1983; Harris-Warrick and Kravitz, 1984; Dixon and Atwood, 1985, 1989a,b; Goy and Kravitz, 1989). 5-HT enhances synaptic transmission at crustacean neuromuscular junctions principally by increasing spontaneous and action-potential-evoked transmitter release from the presynaptic terminal, though a small postsynaptic effect is reported (Dudel, 1965; Enyeart, 1981; Glusman and Kravitz, 1982; Harris-Warrick and Kravitz, 1984).

Three basic mechanisms have been proposed to mediate the increased release of transmitter following 5-HT application: (1) increased steady-state intracellular calcium concentration $\left(\left[\mathrm{Ca}^{2+}\right]_{i}\right)$, which adds with the action-potential-mediated influx to increase the total calcium at release sites; (2) increased actionpotential-mediated calcium influx, either by increased depolarization of the preterminal by the action potential or through a direct effect on vollage-gated calcium channels; and (3) increased effectiveness of the release processes activated by voltage-dependent calcium influx.

Increased resting calcium concentrations might result from a calcium current stimulated directly by $5-\mathrm{HT}$ at or near resting membrane potentials. Alternatively, a $10-\mathrm{mV}$ depolarization caused by 5-HT (Dixon and Atwood, 1985) might activate voltage-dependent calcium channels, producing an accumulation of calcium. However, extracellular calcium is not required during 5-HT application for subsequent excitatory junction potential (EJP) enhancement. The 5-HT-induced depolarization is $\mathrm{Na}^{+}$ dependent (Dixon and Atwood, 1985), so it has been suggested that entry of $\mathrm{Na}^{+}$may secondarily increase resting calcium concentration through enhanced $\mathrm{Na}^{+} / \mathrm{Ca}^{2+}$ exchange. An inositol trisphosphate $\left(\mathrm{IP}_{3}\right)$-stimulated release of stored $\mathrm{Ca}^{2+}$ has also been suggested to contribute to 5-HT-mediated EJP enhancement by increasing resting $\mathrm{Ca}^{2+}$ at least transiently (Dixon and Atwood, 1989a).

5-HT depolarizes the excitor axon and reduces the height of the action potential recorded in the axon near the terminals (Dixon and Atwood, 1985). Moderate continuous depolarization of the axon can increase transmitter release evoked by larger, brief-duration current injections in this preparation (Wojtowicz 
and Atwood, 1984). Because 5-HT is known to increase the excitability of crustacean nerve terminals stimulated extracellularly (Dudel, 1965, 1988), increased calcium influx might result from improved invasion of terminals by action potentials in a depolarized axon if normally the terminals were not fully invaded. There is no evidence for broadening of the presynaptic action potential in crayfish by 5-HT (Dixon and Atwood, 1985), though intracellular recordings from presynaptic terminals have not been made.

Attempts to determine the mechanisms by which neuromodulatory substances alter synaptic efficacy are hampered by the small size of presynaptic terminals, which usually prevents direct electrophysiological measurements. Proposals to explain the effects of neuromodulatory substances at nerve terminals usually represent extrapolations from studies on the more accessible soma membrane and cytoplasm (e.g., Klein and Kandel, 1978). These extrapolations are potentially incorrect because of the nonuniform distribution of channel types and biochemical machinery in different parts of a neuron (Smith et al., 1988; Thompson and Coombs, 1988). Most of the mechanisms previously proposed to explain 5-HT's action at crayfish neuromuscular junction involve calcium metabolism in some way. Therefore, as an adjunct to traditional electrophysiological measurements, we have used a fura- 2 imaging technique that permits direct measurement of cytoplasmic calcium concentrations in presynaptic terminals (Delaney et al., 1989). Our methods permit simultaneous measurement of presynaptic $\left[\mathrm{Ca}^{2+}\right]_{i}$ and postsynaptic junction potentials while applying $5-\mathrm{HT}$. We have examined the effects of 5-HT on basal $\left[\mathrm{Ca}^{2+}\right]_{i}$ as well as on the accumulation of calcium during trains of action potentials, which is an indicator of calcium influx.

\section{Materials and Methods}

Dye filling and physiology. All experiments were performed on the claw opener muscle of the first walking leg of crayfish Procambrus clarkii. The leg was prepared for electrophysiological recording and imaging of $\left[\mathrm{Ca}^{2+}\right]_{i}$ by fura-2 as described previously (Delaney et al., 1989). Action potentials were selectively stimulated in the excitor axon by separating the leg nerve at the level of the meropodite and placing the bundle containing the excitor axon into a plastic suction electrode. Electrophysiological recordings of muscle EJPs were acquired on a Gould chart recorder and as on-line averages of about 30 EJPs using a Nicolet 4094 digital oscilloscope or stored on FM tape and averaged off line on computer.

Fura-2 (22 mM; pentapotassium salt, Molecular Probes, Eugene, OR) in $200 \mathrm{~mm} \mathrm{KCl}, 20 \mathrm{~mm} \mathrm{~K}$-HEPES, pH 7.5, was iontophoresed into the excitor axon via standard-wall glass microelectrodes $(20 \mathrm{M} \Omega$ with $3 \mathrm{M}$ $\mathrm{KCl})$ by injection of continuous hyperpolarizing current (10-15 $\mathrm{nA}, 20$ $30 \mathrm{~min})$. Because fura-2 is a calcium buffer with a relatively fast "on" rate (Kao and Tsien, 1988), it can alter the time course and magnitude of calcium transients in neurons when present at high concentrations. After injection, the fura-2 was allowed to diffuse at least $30 \mathrm{~min}$ before obtaining baseline measurements. Significant overfilling with fura-2, for example, $20 \mathrm{nA}$ for $60 \mathrm{~min}$, reduced the rate of rise and decay of $\left[\mathrm{Ca}^{2+}\right]$ produced by trains of action potentials in terminals near the injection site as well as reducing the size of EJPs. We therefore used conscrvative injection currents and injection times, monitored the intensity of the fluorescence during filling, and checked the time course of recovery of $\left[\mathrm{Ca}^{2+}\right]_{i}$ in terminals following brief trains of action potentials. If the $\left[\mathrm{Ca}^{2+}\right]_{i}$ did not recover completely to prestimulus levels within about $30 \mathrm{sec}$ following a $30-\mathrm{sec}$ train of action potentials at $10 \mathrm{~Hz}$, then another terminal was imaged, and if a branch containing several terminals that matched our criteria could not be found, then the preparation was discarded.

The normal Van Harraveld's saline (NVH) contained $195 \mathrm{mM} \mathrm{Na}^{+}$, $13.5 \mathrm{mM} \mathrm{Ca}^{2+}, 5.4 \mathrm{mM} \mathrm{K}^{+}$, and $2.6 \mathrm{mM} \mathrm{Mg}^{2+}$ supplied as chloride salts, with $10 \mathrm{~mm} \mathrm{Na}{ }^{+}$-HEPES, pH 7.4. Temperature of the preparation was maintained at $18 \pm 2^{\circ} \mathrm{C}$ with a stage-mounted Peltier device. A stock serotonin solution (creatine sulfate, Sigma, St. Louis, MO; $10 \mathrm{~mm}$ in distilled water) was prepared fresh daily and diluted in NVH immediately prior to perfusing onto the preparation. Tetraethylammonium chloride (TEA; Aldrich, Milwaukee, WI) was prepared as a 1-M stock and diluted in NVH immediately prior to perfusion. Reduced calcium salines were prepared by mixing calcium-containing $\mathrm{NVH}$ with saline containing normal $\mathrm{Mg}^{2+}$ but no $\mathrm{Ca}^{2+}$ or calcium buffer. High-osmolarity (HiOsm) salines were prepared by addition of either 150 or $300 \mathrm{~mm}$ sucrose to NVH.

A gravity perfusion system was used for constant perfusing of the surface of the muscle and application of 5-HT. A solenoid-controlled four-way valve (General Valve, series 18, Fairfield, NJ) located near the preparation was used to switch between normal and modified salines. The inflow of the perfusion system was formed from a 1-mm-diameter glass tube pulled to about $0.5 \mathrm{~mm}$ at the tip, which was placed just above the surface of the muscle fibers at the distal end of the claw segment. The outflow was positioned so that flow of saline or drugs over the surface of the muscle was ensured despite the positioning of a $40 \times$ water-immersion lens $1.6 \mathrm{~mm}$ above the muscle surface. We tested the effectiveness of this perfusion system using elevated $\mathrm{K}^{+}$saline and found that the depolarizing effect of high $\mathrm{K}^{+}$measured in a surface muscle fiber began within $20 \mathrm{sec}$, stabilized within about $1 \mathrm{~min}$, and reversed completely within about 2 min following washout. Only a single application of 5-HT was used per preparation.

The preparation was mechanically stabilized by gluing the shell of the claw to the Sylgard surface of the recording dish with a small amount of cyanoacrylate adhesive (Histoacryl Blau, Iri Hawk Industries, Montreal, Canada, or Krazy Glue( $(x)$ ). Movement between acquisition of image pairs results in inaccurate estimates of calcium when using a ratiometric dye such as fura-2. Movement caused by muscle contraction was often a problem during tetanic stimulation after enhancement of synaptic transmission and muscle contractility by 5 -HT. Consequently, we limited the stimulation rate to $5 \mathrm{~Hz}$ or less in NVH. Many of the experiments reported in this article were performed in reduced-calcium salines containing $30 \%, 50 \%$, or $70 \%$ of normal calcium to reduce artifacts associated with movement. The reduction in the amplitude of the EJP produced by perfusion with saline with $30-50 \%$ calcium usually permitted 30-sec trains of 9-16 $\mathrm{Hz}$ to be applied without significant muscle movement.

Imaging of presynaptic terminals. Two imaging systems were used in this study. One system is based on a silicon-intensified target camera (Dage MTI, Model 66) attached to an upright compound microscope (Technical Instruments, Measuremaster II, San Francisco, CA). Excitation wavelengths were controlled using band-pass filters (350 \pm $10 \mathrm{~nm}, 385 \pm 5 \mathrm{~nm}$; Omega Optical, Brattleboro, VT) mounted on a wheel driven by a computer-controlled stepper motor. Excitation and emission wavelengths were separated at $510 \mathrm{~nm}$ with a dichroic mirror, and the autofluorescence was limited using a barrier filter of $510 \pm 10$ $\mathrm{nm}$. Background subtractions and nonuniformity corrections were performed automatically in a Gould FD 5000 (Fremont, CA). Image display was under the control of a Scientific Microsystems (Mountain View, CA) SMS 1000 computer. Sequential 350-nm and 385-nm excited images were stored using an optical disk recorder (Panasonic, TQ-2028F, Secaucus, NJ). In the second system, images are acquired using a 12bit cooled charge-coupled device (CCD; Photometrics, Tuscon, AZ) attached to an upright microscope (Zeiss, model UEM). The system is similar to the one previously used (Delaney et al., 1989). Storage and analysis of images were performed on a Macintosh IIX computer. Alternation of excitation wavelengths $(340 \pm 10 \mathrm{~nm}, 10 \mathrm{~nm}, 380 \pm 5 \mathrm{~nm})$ was achieved with a series of dichroic mirrors and two electronically controlled shutters. An emission barrier filter of $510 \pm 40 \mathrm{~nm}$ was used. Careful attention to the uniformity of the illumination limited the variation of the ratio to less than $5 \%$ across the field of view, so a nonuniformity correction was not applied.

The theory behind the use of fura- 2 to measure calcium concentrations is explained by Grynkiewicz et al. (1985). Upon binding of calcium, the intensity of fluorescence emission at about $510 \mathrm{~nm}$ in response to excitation by wavelengths shorter than $360 \mathrm{~nm}$ increases, while the intensity of excitation with wavelengths longer than $360 \mathrm{~nm}$ decreases. Pairs of ratioed images obtained with $350-\mathrm{nm}$ and $385-\mathrm{nm}$ excitation (at University of California at Berkeley) or 340-nm and 380-nm excitation (AT\&T Bell Labs) were used to calculate $\left[\mathrm{Ca}^{2+}\right]_{i}$ using Equation 5 of Grynkiewicz et al. (1985) after application of a viscosity correction 
factor of 30\% (Delaney et al., 1989). On both systems, a $40 \times$ longworking-distance water objective (Zeiss) was used for fluorescence excitation and imaging. Ratios were acquired using averages of 32 or 64 frames at each excitation wavelength with the SI'I camera; $2 \times 2$ binning of pixels and 400- or 800-msec exposures were typically used with the CCD. We assumed a dissociation constant for fura- 2 in crayfish axoplasm of $865 \mathrm{~nm}$. This value was confirmed by measuring the $350-\mathrm{nm}$ : $385-\mathrm{nm}$ fluorescence ratio of $50 \mu \mathrm{M}$ fura- 2 in a solution of $280 \mathrm{~mm}$ ionic strength with $\left[\mathrm{Ca}^{2+}\right]$ buffered to $500 \mathrm{~nm}$ with $10 \mathrm{~mm}$ EGTA at pH 7.02 using the EGTA calcium affinity of Grynkiewicz et al. (1985). The ratio at saturated calcium divided by ratio at 0 calcium was typically 27 , while the ratio of 385 (or 380 ) $\mathrm{nm}$ excited fluorescence intensity at 0 calcium to 385 (or 380 ) $\mathrm{nm}$ fluorescence intensity at saturated calcium (the free:bound ratio) was approximately 12.

Measurements of $\left[\mathrm{Ca}^{2+}\right]$ were obtained from terminals on intact muscle attached to the shell of the claw. Whenever possible, excitatory junction potentials (EJPs) were recorded from the same fiber or a fiber adjacent to the one upon which the imaged terminals synapsed. Reference background measurements were made from the surface of muscle fibers near the imaged terminals. Considerable care was taken to match the reference background to the background immediately surrounding the imaged terminals and to limit interfering background signals with an adjustable aperture in the excitation light path. In healthy, undamaged preparations, drift in the measured values of $\left[\mathrm{Ca}^{2+}\right]_{i}$ is usually the result of changes in background fluorescence levels. With careful remeasurement of the background calcium, mcasurcments remain constant to within $20-40 \mathrm{~nm}$ over many hours. Sources of backgroundrelated artifacts include changes in the autofluorescence of the muscle fibers, which is normally low but increases when fibers are damaged, changes in the intensity of out-of-focus fura-2 fluorescence from terminals or axon above or below the imaged terminals, and the relative contribution of constant background fluorescence from shell and connective tissue as the intensity of the fura signal changes with fading and diffusion. Because 5-HT has effects on the metabolism of muscle fibers themselves, we were careful to remeasure the background near the end of the 5-HT application to make sure that effects we observed were not due to changes in muscle fluorescence. In all experiments, measurements of $\left[\mathrm{Ca}^{2+}\right]_{i}$ during continuous $0.5-\mathrm{Hz}$ stimulation were obtained for at least $15 \mathrm{~min}$ and more typically $1 \mathrm{hr}$ prior to application of 5-HT, and if, with intermittent remeasurement of the background, resting or basal $\left[\mathrm{Ca}^{2+}\right]_{i}$ was not stable during the control period, the preparation was discarded.

\section{Results}

\section{Effects of 5-HT on basal $\left[\mathrm{Ca}^{2+}\right]_{i}$}

Basal $\left[\mathrm{Ca}^{2+}\right]_{i}$ measured in unstimulated excitor axon was typically 140-190 nм. Stimulation at $0.5 \mathrm{~Hz}$ did not result in a measureable increase in $\left[\mathrm{Ca}^{2+}\right]_{i}$. The maximal effect on resting $\left[\mathrm{Ca}^{2+}\right]_{i}$ observed during application of 5-HT for 5-8 min at concentrations ranging from 5 to $100 \mu \mathrm{M}$ differed between presynaptic terminal boutons and axonal regions (Fig. 1, Table 1).

In most experiments, no effect of $5-\mathrm{HT}$ on resting $\left[\mathrm{Ca}^{2+}\right]_{i}$ was scen in presynaptic boutons located at the ends of long branches or separated from secondary or tertiary axon by thin $(2 \mu \mathrm{m}$ or less) axonal branches. Moderate increases in resting $\left[\mathrm{Ca}^{2+}\right]_{i}$ of 30-60 $\mathrm{nm}$ were sometimes seen in large en passant synaptic swellings of about 5-10 $\mu \mathrm{m}$ across and up to $15 \mu \mathrm{m}$ long, which occur in axons of 2-5- $\mu \mathrm{m}$ diameter. Larger increases, up to 150 $\mathrm{nm}$ in a few preparations, were observed in larger-diameter axons (10-20- $\mu \mathrm{m}$ diameter), where few presumptive presynaptic terminals are present (Jahromi and Atwood, 1974). Axons smaller than $2-5 \mu \mathrm{m}$ were similar to terminal boutons and did not exhibit increased $\left[\mathrm{Ca}^{2+}\right]_{i}$ in the presence of 5-HT. As a result, by the end of a 5-min 5-HT application, a gradient of as much as $100 \mathrm{~nm}\left[\mathrm{Ca}^{2+}\right]_{i}$ can exist over as little as $20 \mu \mathrm{m}$ between a terminal bouton and axonal region, provided the connection is via a thin-diameter axonal branch (e.g., Fig. 1). Therefore, terminals showing little or no increase in resting $\left[\mathrm{Ca}^{2+}\right]_{i}$ during
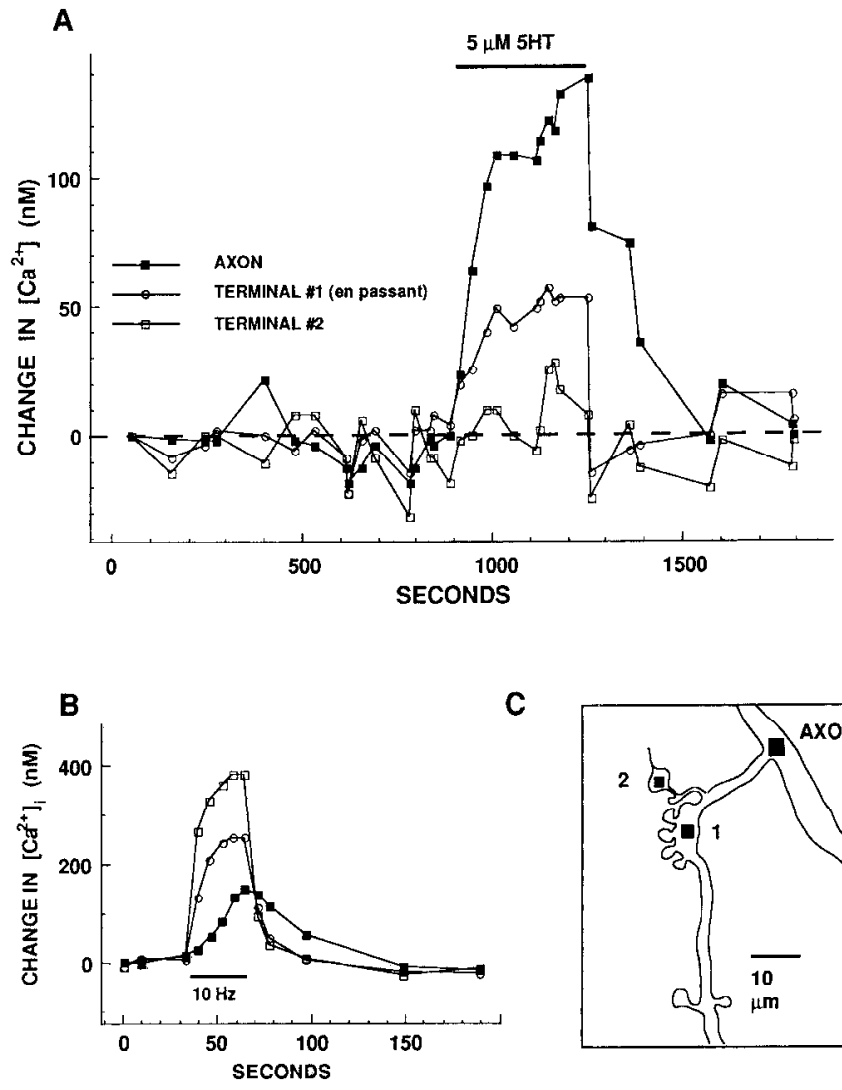

C

Figure 1. Effect of 5-HT on resting calcium in preterminal axon and terminal boutons. $A$, The change in cytoplasmic calcium concentration measured relative to control images obtained at $t=0$ in preterminal axon (solid squares), en passant terminal (open circles), and terminal situated on a small-diameter branch (open squares). 5-HT $(5 \mu \mathrm{M})$ was applied as indicated by the horizontal bar. $B$, Change in calcium concentration measured in the same three locations during and after a 30 sec train of $10-\mathrm{Hz}$ action potentials (horizontal bar). Note the relatively slower rate of rise and fall of calcium in axon as compared to terminal boutons. $C$, Line drawing traced from $380-\mathrm{nm}$-excited fluorescence image indicating locations of regions where calcium was measured for $A$ and $B$.

5-HT application comprise the major portion of synaptic contacts.

The extent to which $\left[\mathrm{Ca}^{2+}\right]_{i}$ increases in response to $5-\mathrm{HT}$ in a particular part of the axonal arborization is inversely correlated with both the magnitude of the $\left[\mathrm{Ca}^{2+}\right]_{i}$ rise during the tetanus and the rate with which $\left[\mathrm{Ca}^{2+}\right]$, decreases in that region following the offset of stimulation (Fig. $1 B$ ). Thus, terminals located on the ends of small-diameter branches or terminals that are arranged like beads on a 1-2- $\mu \mathrm{m}$-diameter "string" of axon show a large and rapid rise in $\left[\mathrm{Ca}^{2+}\right]_{i}$ during a train of action potentials and a rapid return to prestimulus levels following the offset of stimulation, but little or no increase in $\left[\mathrm{Ca}^{2+}\right]_{i}$ during 5-HT application. In many, but not all instances, larger en passant synapses that occur as swellings in $2-5-\mu \mathrm{m}$-diameter axons rise somewhat less quickly and decay somewhat more slowly after tetanic stimulation. $\left[\mathrm{Ca}^{2+}\right]_{i}$ was much slower to increase in larger-diameter axons and much slower to return to rest following even relatively short trains of action potentials. As a consequence, within a few seconds after the offset of a train of action potentials, the calcium gradient is reversed, with calcium concentration higher in axons than in terminals despite 


\begin{tabular}{|c|c|c|c|c|}
\hline Experiment & $\begin{array}{l}\Delta \mathrm{Ca}^{2+} \text { in } \\
\text { terminals } \\
\text { (nM) }\end{array}$ & $\begin{array}{l}\Delta \mathrm{Ca}^{2+} \text { in } \\
\text { axon (nM) }\end{array}$ & {$[5-\mathrm{HT}](\mu \mathrm{M})$} & $\begin{array}{l}{\left[\mathrm{Ca}^{2+}\right]} \\
\text { in } \\
\text { saline }\end{array}$ \\
\hline 1 & $<30$ & - & 100 & $100 \%$ \\
\hline 2 & $<30$ & - & 100 & $100 \%$ \\
\hline 3 & $<30$ & - & 100 & $50 \%$ \\
\hline 4 & $<30$ & - & 50 & $75 \%$ \\
\hline 5 & $<30$ & - & 50 & $30 \%$ \\
\hline 6 & $<30$ & - & 50 & $100 \%$ \\
\hline 7 & $<30$ & - & 50 & $100 \%$ \\
\hline 8 & $<30$ & - & 50 & $50 \%$ \\
\hline 9 & $<30$ & 60 & 50 & $50 \%$ \\
\hline 10 & $<30$ & 60 & 50 & $30 \%$ \\
\hline 11 & $<30$ & $<30$ & 50 & $50 \%$ \\
\hline 12 & $<30$ & - & 50 & $50 \%$ \\
\hline 13 & $30-60^{a}$ & - & 50 & $50 \%$ \\
\hline 14 & $<30$ & - & 50 & $50 \%$ \\
\hline 15 & $<30$ & 120 & 50 & $50 \%$ \\
\hline 16 & $<30$ & $<30$ & 25 & $100 \%$ \\
\hline 17 & $<30$ & - & 20 & $100 \%$ \\
\hline 18 & $<30$ & - & 20 & $100 \%$ \\
\hline 19 & $<30$ & - & 10 & $100 \%$ \\
\hline 20 & $<30$ & - & 10 & $100 \%$ \\
\hline 21 & 30 & $30-60$ & 10 & $100 \%$ \\
\hline 22 & $<30$ & - & 10 & $50 \%$ \\
\hline 23 & $<30$ & - & 5 & $100 \%$ \\
\hline 24 & $<30$ & - & 5 & $50 \%$ \\
\hline 25 & $<30$ & $30-60$ & 5 & $100 \%$ \\
\hline 26 & $<30$ & - & 5 & $30 \%$ \\
\hline 27 & $<30$ & - & 5 & $30 \%$ \\
\hline 28 & $30-60$ & - & 5 & $30 \%$ \\
\hline 29 & $<30$ & - & 5 & $30 \%$ \\
\hline 30 & $30^{b}$ & $90-120$ & 5 & $50 \%$ \\
\hline 31 & $<30$ & - & 5 & $50 \%$ \\
\hline 32 & $<30$ & - & 5 & $50 \%$ \\
\hline 33 & $<30$ & - & 5 & $50 \%$ \\
\hline 34 & $<30$ and $30^{a}$ & $120-150$ & 5 & $50 \%$ \\
\hline 35 & 30 & $90-120$ & 5 & $50 \%$ \\
\hline
\end{tabular}

Data are summary of changes in basal calcium measured in terminals and axon approximately 5 min after starting perfusion of the preparation with 5-HT at concentrations indicated. A different preparation was used in each experiment. - , not measured.

${ }^{a}$ Large en passant terminals.

${ }^{b}$ Terminals near large axon.

smaller peak accumulations in axons (Fig. $1 B$ ). These large axons exhibit the largest increases in $\left[\mathrm{Ca}^{2+}\right]_{i}$ during 5-HT application (Fig. 1A).

Differences in rates of increase and decrease of $\left[\mathrm{Ca}^{2+}\right]_{i}$ seen between small terminal boutons and $5-20-\mu \mathrm{m}$-diameter axons in response to tetanic stimulation are not entirely explained by surface-area:volume considerations in all instances. In response to tetanic stimulation, preterminal axon larger than about $5-\mu \mathrm{m}$ diameter always rises and decays more slowly than terminals even when the surface-area:volume ratio of the axon is greater than or equal to that of terminals in the same field of view. The slow removal of calcium loads by axonal regions as compared to synaptic boutons suggests that accumulation in axon in the response to 5-HT may reflect an inability of this compartment to keep up with a sustained calcium influx across the membrane or release from internal stores. The fact that synaptic boutons rise much more quickly and attain higher average $\left[\mathrm{Ca}^{2+}\right]_{i}$ during tetanic stimulation strongly suggests that there is a greater concentration of voltage-gated calcium channels located in this membrane. It might therefore be expected that these terminal regions would experience greater calcium influx than axon as a result of the 5-HT-mediated depolarization. If so, then the calcium removal systems in the terminal are much more efficient than in the axon, because there is virtually no persistent calcium accumulation in the terminals. Increasing the calcium buffering capacity of the cytoplasm by iontophoretic injection of excess fura-2, EDTA, or EGTA to concentrations estimated to be 1 $\mathrm{mM}$ or greater in terminals results in significant slowing of calcium accumulation during trains of action potentials and recovery after offset of stimulation (Delaney et al., 1990); that is, 
A

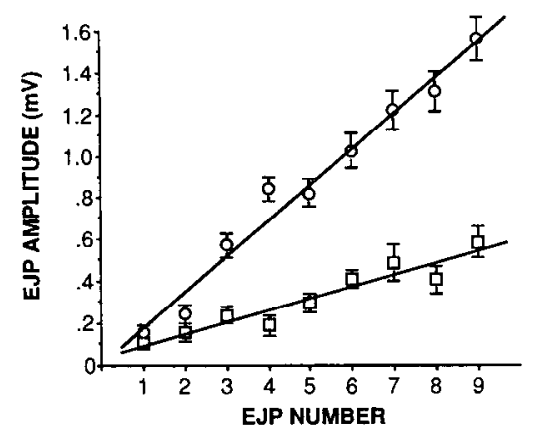

B

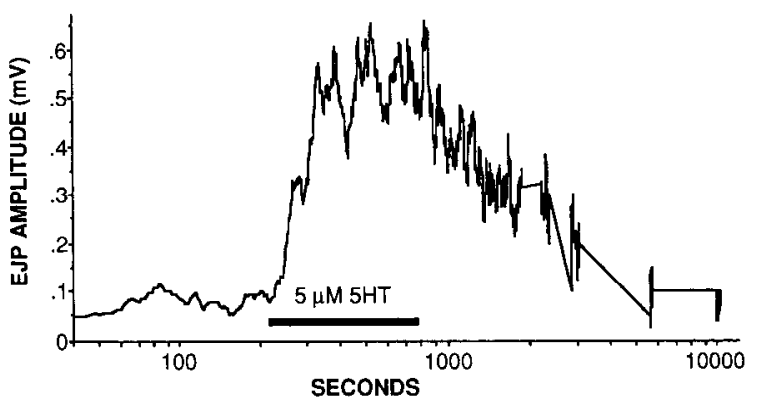

Figure 2. Intracellularly injected EGTA reduces tetanic potentiation but does not block facilitation of the EJP by 5-HT. $A$, Amplitude of the first through ninth EJP in a train stimulated at $10 \mathrm{~Hz}$. Open circles are means \pm SEM for 11 trains of EJPs recorded after penetration of the axon with a pipette containing $100 \mathrm{~mm}$ EGTA but prior to injection of EGTA. The open squares are data from 10 trains obtained after injection of EGTA (10 $\mathrm{nA}$ for $40 \mathrm{~min}$ ), which show that the rate of facilitation of the EJP during the $10-\mathrm{Hz}$ train is reduced. Fitted lines are least-squares regressions: $r^{2}=0.98$ for pre-EGTA and 0.91 post-EGTA. $B$, In the same preparation injected with EGTA, 5 -HT was added to the bath when indicated (horizontal bar) while the excitor motor neuron was stimulated at $0.5 \mathrm{~Hz}$. The effect of 5-HT was normal.

terminals behave like axon when additional calcium buffer is present. Therefore, the difference between axon and terminals could reflect a greater endogenous calcium bufering capacity in axon rather than a difference in the rate of influx and efflux. However, the tendency for $\left[\mathrm{Ca}^{2+}\right]_{i}$ to increase in the axon in response to 5-HT would not be consistent with the presence of greater calcium buffering capacity.

After washout of 5-HT began, any increases in $\left[\mathrm{Ca}^{2+}\right]_{i}$ that had occurred were reversed within a few minutes, even in the axon (Fig. 1 $A$ ), while the enhancement of EJPs developed over the course of drug application and decayed slowly during 60$90 \mathrm{~min}$ of washing, as seen by Dixon and Atwood (1985). Therefore, the longer-lasting effects of 5-HT were definitely not the result of a maintained increase in resting $\left[\mathrm{Ca}^{2+}\right]_{i}$.

These moderate increases in $\left[\mathrm{Ca}^{2+}\right]_{i}$ in axon and slight increases in large en passant terminals were not seen when the preparation was rinsed in calcium-free, 0.5-mM EGTA-NVH prior to and during 5-HT application ( $n=3$ preparations, 5 terminal sites, 3 axon sites), suggesting they were the result of influx rather than internal release.

\section{Intracellular injected EGTA does not block 5-HT-induced synaptic enhancement}

While extracellular calcium is not required for synaptic enhancement by 5-HT, it has been suggested that 5-HT induces the release of calcium from internal stores (Dixon and Atwood, $1989 \mathrm{a})$. If this release were restricted to the region immediately bclow the inner membrane surface near release sites, then it might not produce a large enough change in the fiuorescence signal recorded across the entire volume of the terminal to be detected yet still provide a locally elevated calcium that acts synergistically with action-potential-mediated calcium concentration influx to enhance transmitter release. To test this possibility, we loaded the presynaptic terminals with EGTA to buffer calcium and then applied 5-HT. EGTA is preferred for this purpose because its slightly slower calcium-binding kinetics result in less reduction of the amplitude of the nonenhanced EJP than the faster chelator BAPTA (Adler et al., 1988; Pethig et al., 1989). EGTA was injected by passing $10 \mathrm{nA}$ of negative current for 40-60 min through electrodes containing $100 \mathrm{~mm}$ EGTA, $\mathrm{pH}$ 7.4. Before and during injection, the rate of fre- quency-dependent facilitation of EJPs during 2-sec-long $10-\mathrm{Hz}$ trains was monitored from a muscle fiber near the injection site. Intracellularly injected EGTA had little effect on the amplitude of the first EJP in the train, that is, the nonfacilitated EJP, but reduced the rate of facilitation of EJPs during $10-\mathrm{Hz}$ stimulation (Fig. 2). EGTA slows the accumulation of free calcium in the terminal during stimulation of a train of action potentials, and we presume that this reduces the facilitation normally associated with calcium accumulation. With intracellularly injected EGTA, the release-enhancing effect of 5-HT was not diminished; EJPs stimulated at $0.5 \mathrm{~Hz}$ were enhanced 6.1-, 5.1-, and 5.2-fold in three experiments, comparable to other experiments in this study in which EGTA was not injected and to values reported by Dixon and Atwood (1985). The time to onset of the enhancement was rapid and not discernibly different from control preparations. We feel it unlikely that sufficient calcium could be released internally to saturate the added buffer locally without being detectable by our fura- 2 measurements in the absence of added buffer.

\section{Effects of depolarization on accumulation of $\mathrm{Ca}^{2+}$ in synaptic terminals}

Intraaxonal recordings distal to the characteristic $\mathrm{Y}$ branch, within $100-200 \mu \mathrm{m}$ of the nearest presynaptic boutons, revealed membrane depolarization (approximately $10 \mathrm{mV}$ ) and reduced action-potential amplitude during 5-HT as reported by Dixon and Atwood (1985). This 5-HT-mediated depolarization might be expected to lead to an accumulation of calcium. Therefore, we applied high- $\mathrm{K}^{+}$saline to the preparation to determine how much depolarization was required to cause a detectable increase in $\left[\mathrm{Ca}^{2+}\right]_{i}$ in presynaptic terminals. The depolarizing effect of high- $\mathrm{K}^{+}$saline was measured with an intracellular electrode in the axon distal to the $\mathrm{Y}$ branch during imaging of calcium. Figure 3 shows data from one experiment in which an increase of about $40 \mathrm{~nm}$ is seen in one terminal and less than $20 \mathrm{~nm}$ in another terminal after several minutes of application of saline containing $15.4 \mathrm{~mm} \mathrm{~K}^{+}$, during which the peak depolarization was approximately $13-14 \mathrm{mV}$. An increase in $\left[\mathrm{Ca}^{2+}\right]_{i}$ of about $500 \mathrm{nM}$ is seen when depolarizations of about $25 \mathrm{mV}$ are achieved by applying $\mathrm{K}^{+}$concentrations of $25.4 \mathrm{~mm}$. $\left[\mathrm{Ca}^{2+}\right]_{i}$ increases quickly as the membrane is depolarized more than about $17-19 \mathrm{mV}$. 


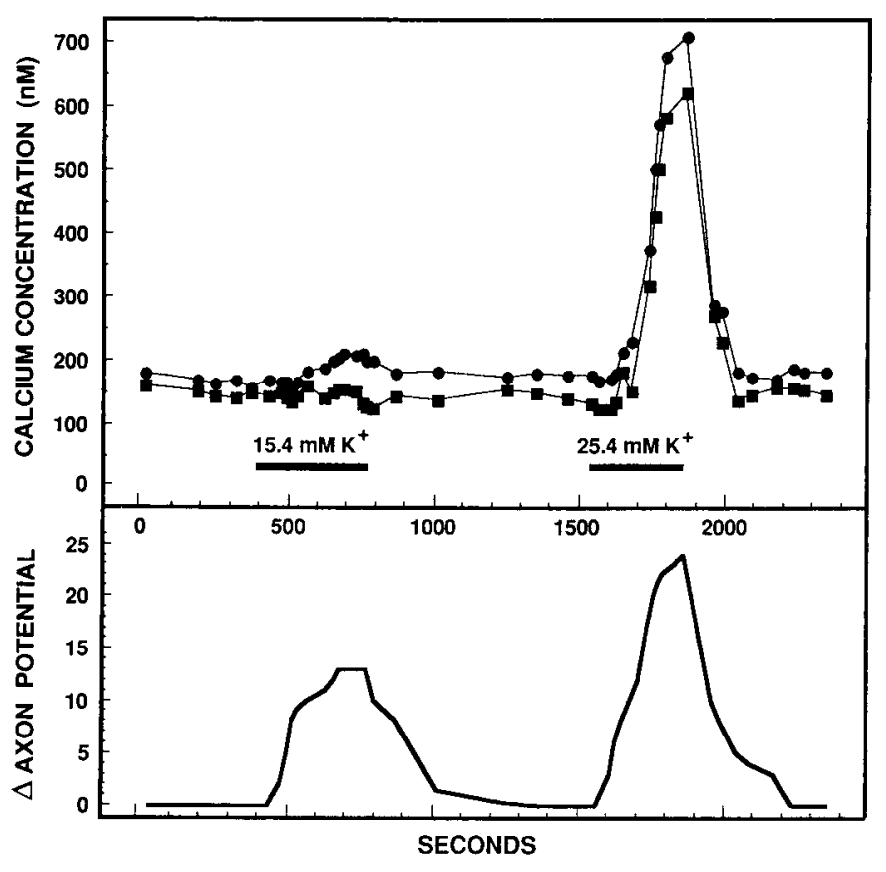

Figure 3. Changes in calcium during $\mathrm{K}^{+}$depolarization. The top panel shows the calcium concentration measured in two terminals (circles, squares) during application of saline containing an additional 10 or 20 $\mathrm{mm} \mathrm{K}^{+}$as indicated (horizontal bars; normal is $5.4 \mathrm{~mm}$ ). The bottom panel shows change in membrane voltage (in $\mathrm{mV}$ ) measured in axon distal to the $\mathrm{Y}$ branch.

This experiment was repeated in three different preparations with virtually identical results. We estimate, therefore, that the 5-HT-induced depolarization that is approximately $10 \mathrm{mV}$ in the axon (data not shown; Dixon and Atwood, 1985) must be less than about $15 \mathrm{mV}$ at the presynaptic terminals, because 5-HT does not typically elevate $\left[\mathrm{Ca}^{2+}\right]_{i}$ in terminals more than $30 \mathrm{nM}$ and slightly larger depolarizations elevate calcium greatly.

\section{Effects of 5-HT on influx and accumulation of calcium during trains of action potentials}

Nerve terminals (between 2 and $15 \mu \mathrm{m}$, with imaged terminals typically $5-8 \mu \mathrm{m}$ ) are covered in connective tissue or buried in folds of muscle fibers and have not been successfully voltage clamped with microelectrodes; thus direct measurement of $\mathrm{Ca}^{2+}$ influx as current is at present impractical. The fura- 2 fluorescence provides a measure of the accumulation of calcium in the terminal during the train. This accumulation represents the balance between influx, buffering, sequestration, and extrusion of calcium. Although the technique cannot easily distinguish between the effect of an increased influx from either a decreased huffering or decreased efflux of calcium, we nevertheless attempted to determine the effects of 5-HT on the influx of calcium by comparing the $\left[\mathrm{Ca}^{2+}\right]_{i}$ reached during trains of action potentials before, during, and after treatment with 5-HT.

5-HT greatly increases excitation-contraction coupling in crustacean muscle (Fischer and Florey, 1983; Harris-Warrick and Kravitz, 1984), with the result that even low-frequency stimulation leads to contraction of the muscle after exposure to 5-HT. To avoid movement artifacts after treatment with 5-HT, stimulation frequencies were limited to $5 \mathrm{~Hz}$ or less unless extracellular calcium was reduced. As a result, the total increase in $\left[\mathrm{Ca}^{2+}\right]_{i}$ seen during the tetanus was limited to around $150 \mathrm{nM}$.
To improve our ability to detect small increases in the actionpotential-evoked calcium influx, we needed to increase the magnitude of the accumulation during the train. By lowering the calcium content of the saline to $30 \%$ or $50 \%$ of normal, we were able to increase the frequency of stimulation without causing contraction. This is possible because with reduced external calcium the accumulation of $\left[\mathrm{Ca}^{2+}\right]_{i}$ during a train is reduced proportionately less than the size of the EJP. We were thus often able to stimulate at frequencies between 8 and $16 \mathrm{~Hz}$ during application of $5 \mu \mathrm{M} 5$-HT in $50 \%$-calcium NVH before movement became a problem. This resulted in accumulations of up to $500 \mathrm{~nm}$ from resting levels of $150-200 \mathrm{nM}$, that is, changes in $\left[\mathrm{Ca}^{2+}\right]_{i}$ of approximately $300 \mathrm{nM}$.

We never saw increased action-potential-mediated calcium accumulation during or immediately after several minutes of 5-HT application. In several experiments, a slight decrease in accumulation was seen with trains during 5-HT application. Accumulations to the first train during or immediately after 57 min of $5 \mu \mathrm{M} 5-\mathrm{HT}$ application were $89 \%$ of the mean accumulation calculated from the two or three trains preceding 5-HT in preparations stimulated in 50\%-calcium NVH (range, 74$100 \%$ measured in 16 terminals; one to three terminals measured per preparation from four preparations in $30 \%$ calcium and seven in $50 \%$ calcium). Figures 4 and $5 \mathrm{~A}$ are typical of the effect of 5-HT on calcium accumulation during trains of action potentials.

Estimates of the change in calcium current required to produce three- to fivefold enhancement assuming a nonlinear (i.e., third to fifth order) relationship between calcium current and release indicated that we would be able to detect such a change if it translated directly to an increased accumulation. However, changes in accumulation may be smaller than changes in calcium influx if removal mechanisms increase their efficiency in the face of increased loading. Therefore, we attempted to determine experimentally how an increased influx would affect calcium accumulation during trains of action potentials by increasing extracellular calcium and by broadening the presynaptic action potential with TEA in amounts that produced similar enhancement of the EJP as 5-HT.

Conditions that enhance $\mathrm{Ca}^{2+}$ influx and enhance the EJP to the same extent as 5-HT are accompanied by measurable increases in $\mathrm{Ca}^{2+}$ accumulation

Figure 5 is representative of three experiments in which $\mathrm{Ca}^{2+}$ accumulation during action-potential trains in 50\% external calcium was measured before, during, and after 5-HT application and when extracellular calcium was subsequently increased from $50 \%$ to $100 \%$ of normal. As shown above, a slight decrease in $\mathrm{Ca}^{2+}$ accumulation is sometimes observed despite enhancement of the EJP (4.4-fold in this experiment). After washout of the 5-HT and return of the EJP to pre-5-HT amplitudes, the extracellular $\mathrm{Ca}^{2+}$ was increased to $100 \%$. This resulted in an increase in the EJP to a size nearly equal to that seen during 5-HT application. Concomitant with this enhancement of EJP amplitude when extracellular $\mathrm{Ca}^{2+}$ was increased from $50 \%$ to $100 \%$ of normal, a clearly measurable increase in the accumulation of $\mathrm{Ca}^{2+}$ was seen. Similar results were obtained in four more experiments in which calcium accumulations were measured when calcium was increased from $50 \%$ to $100 \%$ without also testing the effect of 5-HT. In one preparation, accumulations were compared when calcium was increased from $30 \%$ to $70 \%$. In these eight preparations, calcium accumulations during action-poten- 


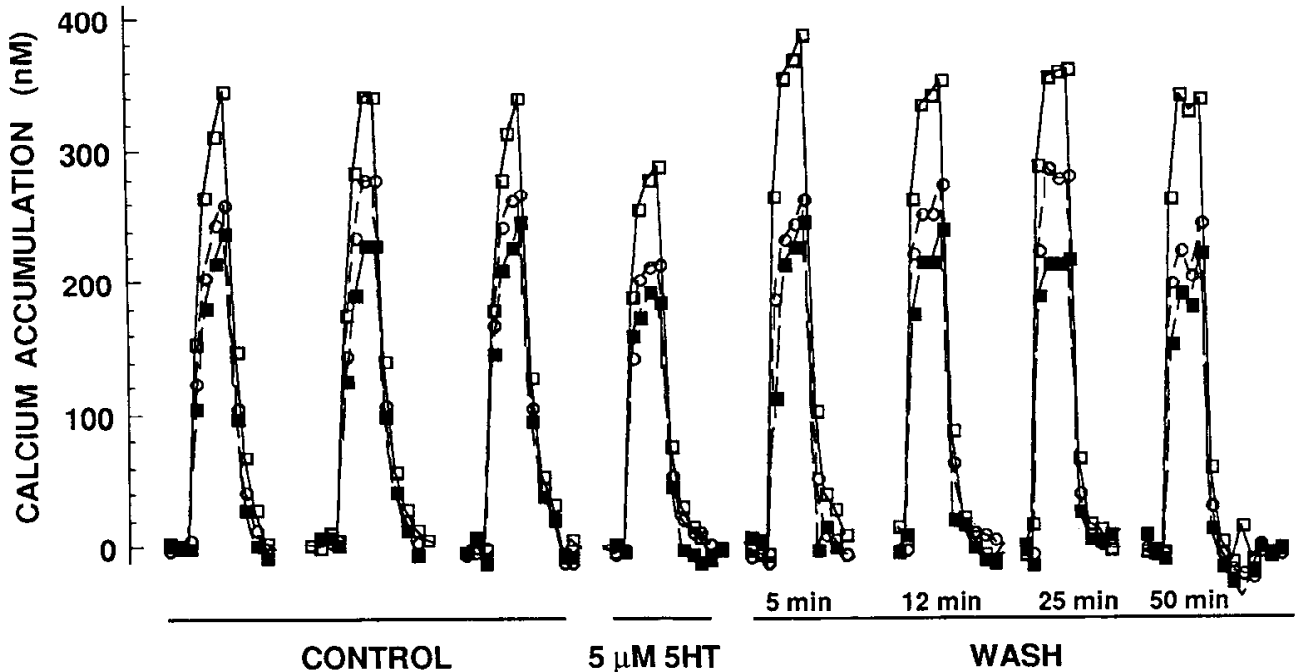

Figure 4. 5-HT produces either no increase or a slight reduction in the accumulation of calcium during trains of action potentials. The change in calcium concentration measured at 5-sec intervals during and after trains of $10-\mathrm{Hz}$ stimulation is shown. Note the slight reduction in the concentration of calcium that accumulates in the terminals when the train of action potentials is stimulated after $5 \mathrm{~min}$ exposure to $5 \mu \mathrm{M}$ 5-HT. After washing out the 5-HT, the accumulation of calcium during trains of action potentials returns to control levels. Extracellular calcium is $6.75 \mathrm{~mm}$. Responses in three separate terminals (indicated by different symbols) from one experiment are shown. tial trains increased an average of $27 \%$ (17-39\%) when extracellular calcium was doubled, while EJP amplitude increased an average of $340 \%$ ( $220-445 \%$; see Fig. 7). Increasing the extracellular calcium from $30 \%$ to $50 \%$ produced a similar three- to fourfold enhancement of EJP amplitude and increase in accumulation in two other experiments where 5-HT failed to increase accumulation. For our purposes, the exact quantitative relationships between influx and accumulation and between in-

A

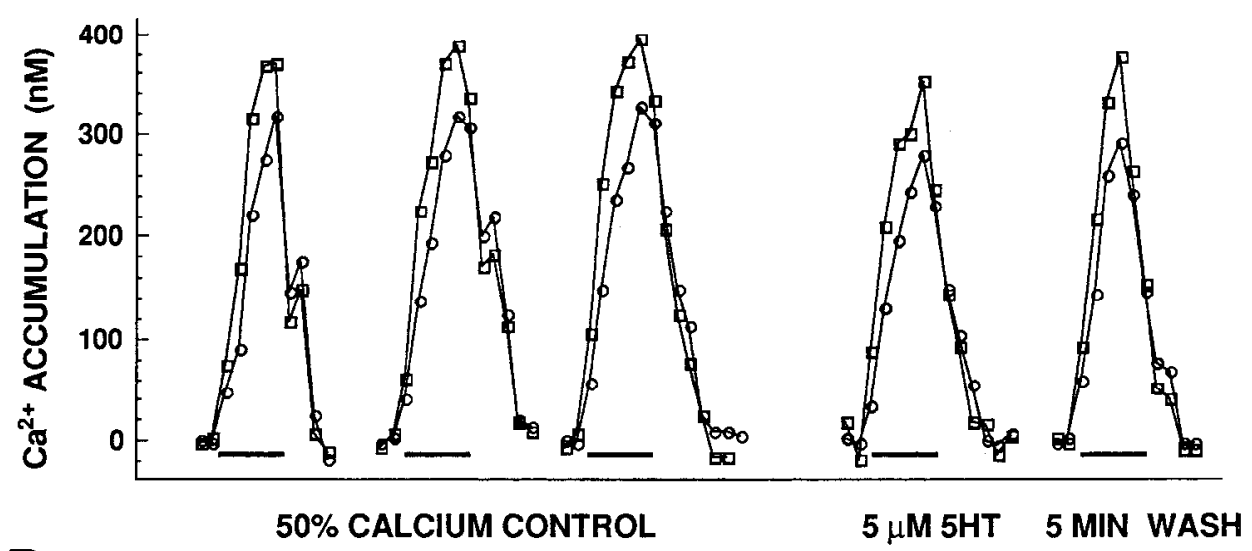

B

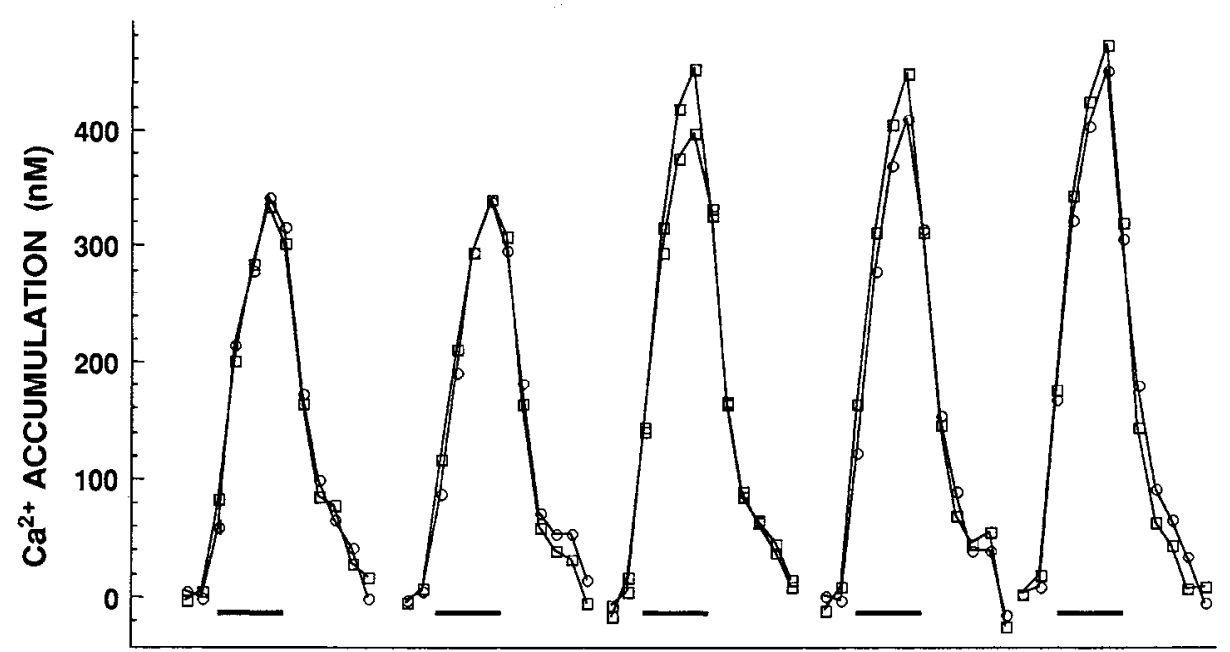

$50 \%$ CALCIUM
Figure 5. 5-HT does not produce an increased accumulation of calcium during trains of action potentials, but increasing extracellular calcium does produce increased accumulation. $A$, Calcium concentration measured at 5sec intervals during and after 25 -seclong $8.3-\mathrm{Hz}$ trains (indicated by horizontal bars) stimulated in NVH containing $6.5 \mathrm{~mm}$ calcium. Despite a 4.5 fold facilitation of the unitary and tetanically facilitated EJP after 6 min of $5 \mu \mathrm{M} 5-\mathrm{HT}$, an increase in accumulation of calcium during trains of action potentials is not seen. $B$, After washing the preparation for approximately 90 min, the 5-HT-induced facilitation of the EJP was reversed. Calcium accumulations during two trains of action potentials stimulated at $8.3 \mathrm{~Hz}$ in 6.5 mM-calcium NVH (50\% calcium) are shown on the left. After rinsing the ganglion for $15 \mathrm{~min}$ in $\mathrm{NVH}$ containing $13.5 \mathrm{~mm}$ calcium (100\% calcium), the EJP was facilitated 4.1-fold, and an increased accumulation of calcium (about $30 \%$ ) is seen. 

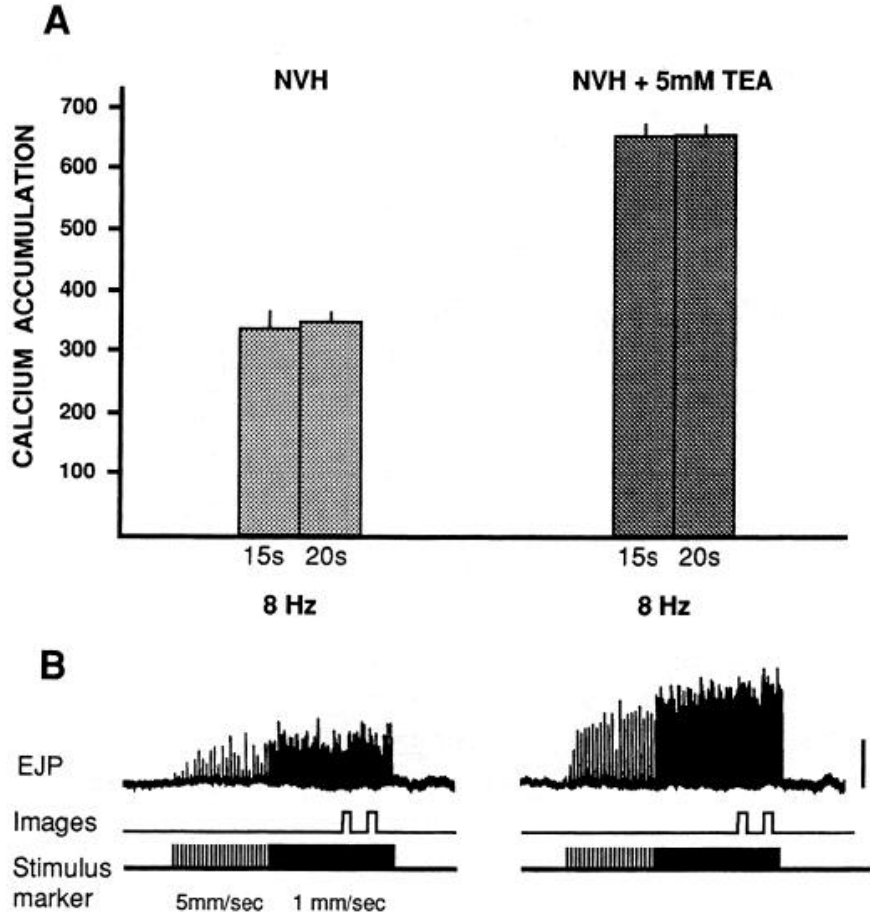

Figure 6. Effect of TEA on EJP amplitude and calcium accumulation during trains of action potentials. A, Bars indicate mean \pm SEM for three terminals measured at $15 \mathrm{sec}$ and $20 \mathrm{sec}$ of continuous stimulation at $8.3 \mathrm{~Hz}$ before and after addition of $5 \mathrm{~mm}$ TEA. EJPs recorded from the same muscle fiber that the imaged terminals synapsed on are shown in the top trace of $B$. The middle trace indicates the points at which the two measurements of calcium concentration were obtained, while the bottom trace is the nerve stimulus marker. The chart recorder speed was $5 \mathrm{~mm} / \mathrm{sec}$ for approximately the first $3 \mathrm{sec}$ to show the initial rate of potentiation, then was slowed to $1 \mathrm{~mm} / \mathrm{sec}$ for the rest of the record. The vertical bar at the right indicates $1 \mathrm{mV}$. Extracellular calcium was $6.75 \mathrm{~mm}$.

flux and release are not important. Instead, the important observation is that 5 -HT produces up to 4.5 -fold enhancement of the EJP without increasing accumulation during trains, yet doubling the extracellular calcium concentration enhances EJPs about fourfold with a clearly detectable increase in calcium accumulation (about 30\%).

TEA is known to broaden the action potential and increase the size of EJPs in crayfish (Zucker, 1974). Figure 6 clearly shows that an increase in EJP amplitude resulting from application of $5 \mathrm{~mm}$ TEA is associated with an increase in the accumulation of calcium during trains of stimuli. In this experiment, an $85 \%$ increase in calcium accumulation with addition of $5 \mathrm{mM}$ TEA is associated with a 2.5-fold enhancement of the EJP measured during a brief train of action potentials. Similarly large increases in accumulation relative to enhancement of the EJP were seen in six other experiments using TEA (Fig. 7). Thus, when the EJP is comparably enhanced by increasing extracellular calcium or spike broadening, a greater accumulation of calcium results with spike broadening. The above-reported values for enhancement of the EJP are for tetanically potentiated EJPs measured during trains of stimuli. TEA enhances EJPs stimulated at moderate frequencies more than unitary EJPs (Wojtowicz and Atwood, 1991; K. Delaney, D. W. Tank, and R. S. Zucker, unpublished observations). The increase in the magnitude and rate of frequency-dependent facilitation in TEA-NVH is thus as-

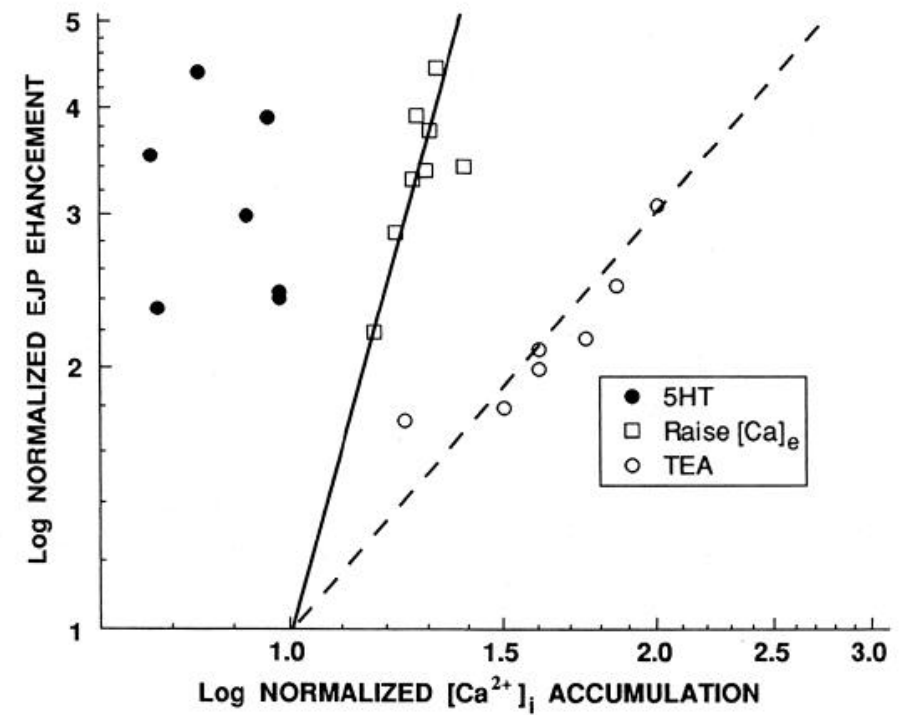

Figure 7. Relationship between accumulation of calcium during tetanic stimulation and enhancement of EJP. Each point indicates results from a different experiment, except for two of the experiments in which the concentration of extracellular calcium was changed and one of the TEA experiments, which are from the same preparations used to show the effect of 5-HT. Increasing extracellular calcium concentration from $50 \%$ to $100 \%$ or from $30 \%$ to $70 \%$ of normal and addition of $3-5 \mathrm{~mm}$ TEA both produced an increased accumulation during trains of stimuli, while 5-HT-enhanced transmitter release is associated with a slight decrease in accumulation. Broken and solid lines indicate normalized $\left[\mathrm{Ca}^{2+}\right]$ raised to powers of 1.6 and 5 , respectively.

sociated with an increased accumulation of calcium during a train of action potentials. Injection of TEA into the axon or perfusion of the preparation with $0.5-1 \mathrm{~mm}$ 4-aminopyridine also increases the EJP amplitude and at the same time results in greater accumulations of calcium during trains of action potentials (data not shown). 5-HT neither increases the accumulation of calcium during trains of action potentials nor increases the rate or magnitude of frequency-dependent facilitation (present results; see also Fischer and Florey, 1983; Dudel, 1988), which provides further evidence that it probably does not cause broadening of the action potential similar to that produced by TEA.

Figure 7 compares the results of 5-HT application, increasing extracellular calcium, and addition of TEA on accumulation and EJP enhancement. From these experiments, we conclude that changes in action-potential-mediated influx are manifested as changes in $\mathrm{Ca}^{2+}$ accumulation during trains and that our failure to observe an effect of 5-HT on accumulation of calcium during trains of action potentials is not due to the relevant changes being too small to detect. The possibility remains that, in addition to increasing calcium influx during each action potential, 5-HT simultaneously increases the rate of removal or sequestration just enough to balance the increased influx.

\section{Effects of 5-HT on spontaneous transmitter release}

Addition of $5 \mu \mathrm{M} 5$-HT to normal saline causes an increase in the frequency of spontaneous miniature EJPs (mEJPs). Spontaneous release rates were normally less than $1 / \mathrm{sec}$ before addition of 5-HT, similar to rates reported by Dudel (1965) but lower than those reported by Lando et al. (1986). 5-HT increased the frequency of mEJPs about threefold in five experiments where mEJPs were measured in addition to EJPs, similar to the 
effect reported by others (Dudel, 1965; Glusman and Kravitz, 1982; Niles and Smith, 1982). Therefore, 5-HT increases the rate of release of mEJPs in fura-2-injected terminals without a widespread increase in resting $\left[\mathrm{Ca}^{2+}\right]_{i}$.

We also examined the effect of 5-HT on spontaneous release rate under conditions where the release rate was elevated by addition of $300 \mathrm{~mm}$ sucrose to the saline. This improved our resolution of the effects of 5-HT on $\mathrm{mEJP}$ frequency by increasing the overall rate of $\mathrm{mEJPs}$ and allowed us to explore further the calcium independence of the effects of 5-HT.

Application of HiOsm saline to crayfish (Van der Kloot and Kita, 1974; Lando et al., 1986), frog (Kita and Van der Kloot, 1977; Barton et al., 1983), and mouse (Hubbard et al., 1968) neuromuscular junctions increases the rate of spontaneous mEJPs. It has been proposed that this increased release is due to increased $\left[\mathrm{Ca}^{2+}\right]_{i}$ resulting from the extrusion of water from the terminal (Cohen and Van der Kloot, 1985). We observed shrinkage of the terminal following application of HiOsm saline as well as an increase in the fura- 2 fluorescence intensity of the terminal. Both these observations are consistent with the idea that water was being extruded from the terminal because the concentration of ions in the cytoplasm increases in proportion to the volume change, while the fluorescence intensity is a function of both concentration and path length. The fluorescence ratio did not change much when HiOsm saline was added (Fig. $8 A$ ). This is to be expected given the effect of ionic strength on fura- 2 dissociation constant (Poenie et al., 1986). As the extracellular osmolarity, and thus the ionic strength, of the cytoplasm increase, the fluorescence ratio corresponding to any given $\left[\mathrm{Ca}^{2+}\right]_{i}$ decreases proportionately so that the measured ratio remains essentially unchanged despite the increasing $\left[\mathrm{Ca}^{2+}\right]_{i}$. We assumed the effect of increased osmolarity of the saline translated into an equal increase in osmolarity of the cytoplasm and increased the dissociation constant used in the calculation of $\left[\mathrm{Ca}^{2+}\right]_{i}$ correspondingly. Figure $8 B$ shows that this results in an increase of approximately $125 \mathrm{~nm}$ in resting $\left[\mathrm{Ca}^{2+}\right]_{i}$ when $\mathrm{NVH}$ with 300 $\mathrm{mm}$ sucrose is added. After correcting for the increase in dissociation constant that occurs with increased osmolarity, the accumulation of calcium during a train of action potentials appears similar to that in normal saline (Fig. $8 B$ ).

The increase in spontaneous mEJPs that occurred with addition of HiOsm saline often showed an initial peak that decayed to a steady state within a few minutes. This peak was not always observed and may relate to the effects of the shrinking of the muscle fibers and terminals during the osmotic equilibration. The frequency of mEJPs was increased 5.6-fold (range 2.3-15.7) between 3 and 5 min after the addition of 300-mm-sucrose saline in eight experiments. The effect of HiOsm saline on EJP amplitude was less (2.1-fold; range $1.2-3.4 ; n=7$ ) than the effect on mEJP frequency. This difference has been observed before (Niles and Smith, 1982; Barton et al., 1983). The effect of $5 \mu \mathrm{M}$ 5-HT on mEJPs and EJPs in HiOsm saline was similar to that in NVH. Addition of 5-HT to the HiOsm saline resulted in an additional 3.6-fold (range $1.6-11 ; n=8$ ) increase in the frequency of mEJPs and the usual increase in the amplitude of EJPs stimulated at $0.5 \mathrm{~Hz}(5.3$-fold; range $2.4-11.8 ; n=6)$ as measured after $5 \mathrm{~min}$. As with experiments using normal-osmolarity saline, no further increase in the resting $\left[\mathrm{Ca}^{2+}\right]_{i}$ was seen in synaptic terminals during 5-HT application in these HiOsm experiments despite increases in frequency of mEJPs. This observation is not subject to any error in correcting for osmolarity-related changes in the calcium affinity of fura- 2 .
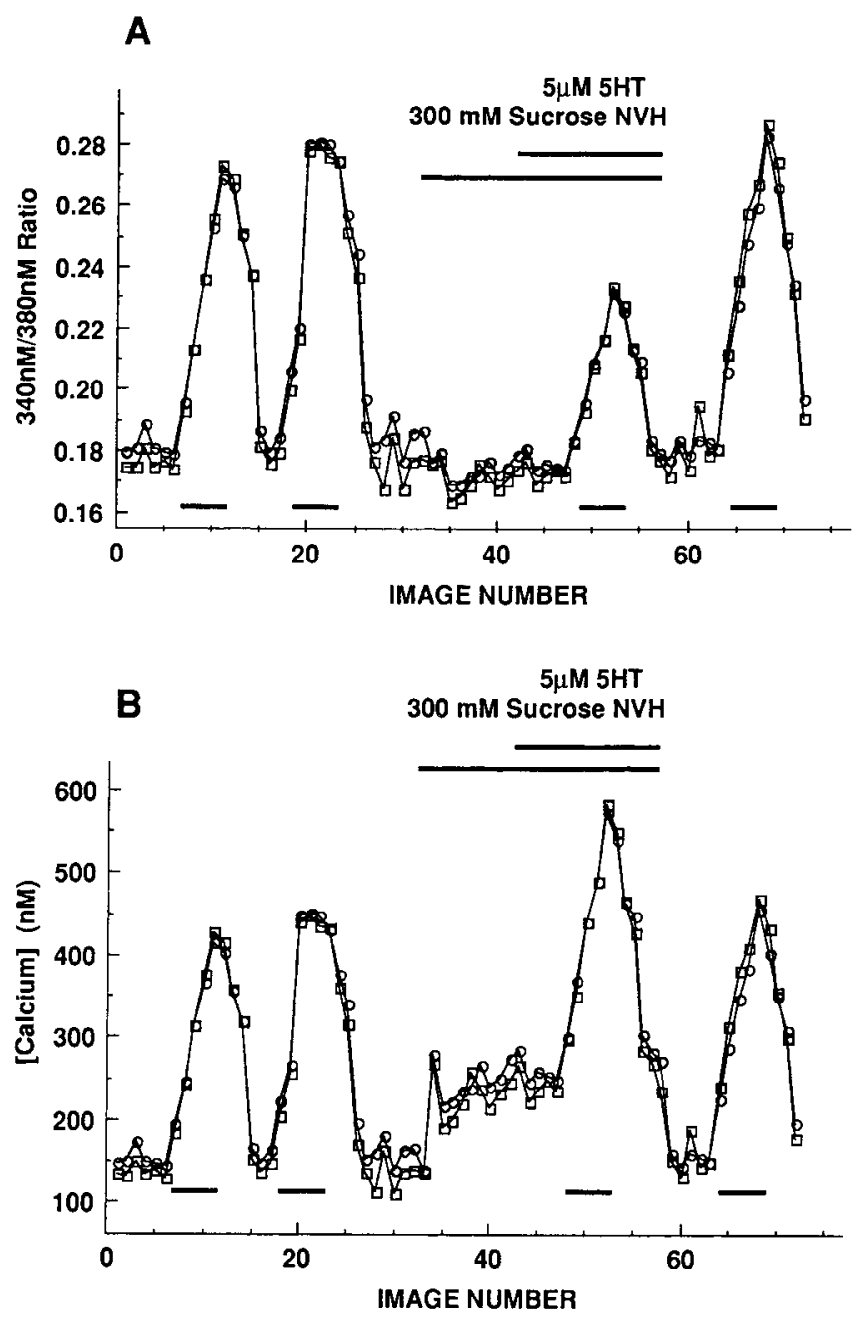

Figure 8. HiOsm saline increases cytoplasmic calcium concentration. $A$, Ratio of 340-nm to 380-nm excited fluorescence before, during, and after application of saline with $300 \mathrm{~mm}$ sucrose added. Measured osmolarity increased from 440 to $750 \mathrm{mOsm}$ with addition of sucrose during period indicated by lower horizontal bar in $A$ and $B$. Note that neither increasing osmolarity nor addition of 5-HT to this sucrosesaline increased 340-nm:380-nm ratio. In HiOsm saline plus 5-HT, the change in ratio during an $8.3-\mathrm{Hz}$ train of action potentials is less than in normal saline. $B$, Conversion of fluorescence ratios to calcium concentrations with the dissociation constant for fura- 2 adjusted for the increased ionic strength inside the terminal due to the increased extracellular osmolarity during the period indicated by the lower horizontal bar. During a 5-min application of 5-HT, no further increase in $\left[\mathrm{Ca}^{2+}\right]_{i}$ is seen, and the accumulation during an $8.3-\mathrm{Hz}$ train is similar to that before and after 5 -HT plus HiOsm saline.

\section{Discussion}

Calcium is a necessary and sufficient stimulus for release of neurotransmitter (Miledi, 1973; Llinas et al., 1987; Zucker and Haydon, 1988; Delaney and Zucker, 1990). Changes in voltagedependent calcium influx (Llinas et al., 1981; Augustine et al., 1985; Augustine and Charlton, 1986) and resting or "steadystate" calcium concentration (Charlton et al., 1982; Delaney et al., 1989) modulate transmitter release. The extent to which the exocytotic apparatus responds to a given concentration of calcium appears to be modifiable (Knight et al., 1989; Man-SonHing et al., 1989; Dale and Kandel, 1990). Thus, there are many ways in which a neuromodulatory substance can affect neurotransmission by affecting the link between calcium and trans- 
mitter relcasc. Our fura-2 fluorescence imaging experiments indicate that 5-HT increases transmitter release at crayfish neuromuscular junction without increasing resting calcium or action-potential-mediated calcium influx.

\section{Increased resting calcium concentration is not responsible for 5-HT enhancement of transmitter release}

The use of microscopic imaging of fura-2 fluorescence combined with the relatively small size of the terminal boutons means that our measurements of cytoplasmic calcium concentrations at rest probably accurately reflect the average steadystate calcium at transmitter release sites. An effect of highly localized buffering of calcium near release sites on the inner surface of the membrane cannot be ruled out solely on the basis of our imaging data. The spatial resolution of the imaging system, approximately $1 \mu \mathrm{m}$ in the horizontal plane, revealed that axonal and presynaptic boutons reacted differently to 5-HT. Terminal boutons maintained constant or nearly constant cytoplasmic calcium concentrations, while spontaneous and action-potential-evoked transmitter release increased. Axons greater than a few microns in diameter showed small but reliable increases in resting calcium concentration during and immediately after 5-HT application. Experiments in which elevated $\mathrm{K}^{+}$was used to depolarize the axon suggest that the small increases in basal calcium seen during 5-HT application can be accounted for by the depolarizing effects of 5-HT, which are estimated to be greater than $10 \mathrm{mV}$ in presynaptic terminals based on measurements made in nearby axon (Dixon and Atwood, 1985).

If an increase in resting $\left[\mathrm{Ca}^{2+}\right]_{i}$ were responsible for enhancement of the EJP, then how much of an increase would be necessary to produce the observed three- to fivefold enhancement? Is the required increase in $\left[\mathrm{Ca}^{2+}\right]_{i}$ within the sensitivity of our $\mathrm{Ca}^{2+}$-measurement system? Using the relationship found between $\left[\mathrm{Ca}^{2+}\right]_{i}$ and potentiation of the EJP following the offset of $7 \mathrm{~min}$ of $33-\mathrm{Hz}$ tetanic stimulation by Delaney et al. (1989, their Fig. 2), we estimate that three- to fivefold enhancement of EJP amplitude should be accompanied by a widespread increase in resting $\left[\mathrm{Ca}^{2+}\right]_{i}$ of $150-250 \mathrm{nM}$ in presynaptic terminals. Increases approaching this magnitude were seen infrequently and then only in smooth axonal regions greater than $5 \mu \mathrm{m}$ in diameter (which presumably do not release transmitter) at the end of $5 \mathrm{~min}$ of $5-\mathrm{HT}$ application, and these disappeared rapidly after washout of 5-HT. Although this calculation should be treated with caution, because factors other than the steady-state $\left[\mathrm{Ca}^{2+}\right]_{i}$ might contribute to the amount of potentiation following minutes-long tetanic stimulation, more recent experiments that examine the relationship between steady-state $\left[\mathrm{Ca}^{2+}\right]_{i}$ and shortlasting augmentation of transmitter release indicate that this same quantitative relationship between $\left[\mathrm{Ca}^{2+}\right]_{i}$ and augmentation is seen regardless of how $\left[\mathrm{Ca}^{2+}\right]_{i}$ is raised (Delaney et al., 1990). We therefore conclude that the increases in $\left[\mathrm{Ca}^{2+}\right]_{i}$ we observe during 5-HT application are mostly restricted to regions that do not release transmitter and are too small to account for the magnitude of synaptic enhancement produced by $5-\mathrm{HT}$.

Calcium accumulation during 5-HT was dependent upon the presence of extracellular calcium. This suggests that the moderate increases in $\left[\mathrm{Ca}^{2+}\right]_{i}$ in axon are due to influx rather than release from intracellular stores. Whether these axonal increases in calcium are due to opening of voltage-gated calcium channels or a shift in the balance between inward $\mathrm{Ca}^{2+}$ leak and $\mathrm{Ca}^{2+}$ extrusion is not yet known. Although it is possible that depletion of the intracellular calcium stores occurs during $30 \mathrm{~min}$ of exposure to calcium-free saline so that 5 -HT-stimulated $\mathrm{Ca}^{2+}$ release cannot occur, previous studies have indicated that removal of extracellular calcium during 5-HT application does not block expression of enhanced transmitter release when calcium is subsequently returned to the bath (Glusman and Kravitz, 1982; Dixon and Atwood, 1985). Therefore, a 5-HT-induced increase in EJP amplitude can occur in the absence of a rise in preterminal $\left[\mathrm{Ca}^{2+}\right]_{i}$, and it is unlikely that the small increases in $\left[\mathrm{Ca}^{2+}\right]_{i}$ we observe in axon bathed in NVH have an important role in enhancement of transmitter release by 5-HT. Our data also suggest that release of calcium from intracellular stores, either by $\mathrm{IP}_{3}$ or sodium, sufficient to overcome calcium removal systems does not occur in terminals. Our observation that intracellularly injected EGTA does not diminish the ability of 5-HT to enhance the EJP corroborates our imaging data and indicates that local undetectable increases in $\left[\mathrm{Ca}^{2+}\right]_{i}$ also are not likely to underlie 5-HT's effects.

\section{$I P_{3}$ may play a calcium-independent role in 5-HT enhancement of transmitter release}

Phosphatydilinositol 4-5 bisphoshphate (PIP ${ }_{2}$ ) breakdown and the production of $\mathrm{IP}_{3}$ and diacylglycerol have been implicated in mediating some of the effects of 5-HT. Dixon and Atwood $(1989 a, b)$ suggest that the early, more rapidly decaying effects of 5-HT might be mediated by production of $\mathrm{IP}_{3}$ and a transient increase in intracellular calcium concentration. Our data are inconsistent with $\mathrm{IP}_{3}$-induced calcium release mediating part of 5-HT's effects, but $\mathrm{IP}_{3}$ may act in some other way to enhance transmitter release. It is possible that 5 -HT stimulation produces $\mathrm{IP}_{3}$, but if it releases calcium from internal stores in the terminal and the axon, then the release is neither sufficient to overcome the buffering and extrusion capacity of the terminal (hence our failure to see a calcium increase) nor necessary for enhanced transmitter release (hence the failure of intracellular EGTA to block the effect of 5-HT). In the experiments of Dixon and Atwood (1989a), injection of $\mathrm{IP}_{3}$ produced huge increases in miniature frequency (more than 10-fold greater than that produced by $5-\mathrm{HT}$ ), so it is highly unlikely that the levels of $\mathrm{IP}_{3}$ resulting from their injections were comparable to those that might be produced by $5-\mathrm{HT}$.

IP $_{3}$ appears to be capable of exerting effects on some ion channels that are not mediated by elevation of intracellular calcium concentration (Dutar and Nicoll, 1988; Scholz et al., 1988), and perhaps $\mathrm{IP}_{3}$ is capable of modulating transmitter release independent of an increase in $\left[\mathrm{Ca}^{2+}\right]_{i}$. We do not, however, see evidence for changes in voltage-dependent calcium influx, so the effect is probably not on presynaptic calcium channels. None of our data contradict a possible role for other prod-

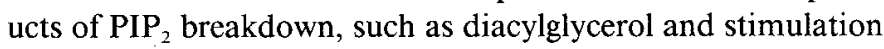
of protein kinase C activity, as suggested by Dixon and Atwood (1989a), though translocation of cytosolic protein kinase $C$ to the membrane must be occurring under conditions of nonelevated $\left[\mathrm{Ca}^{2+}\right]_{i}$ (Huank, 1989).

\section{Action-potential-mediated calcium influx is not increased by 5-HT}

Considering the nonlinear relationship between calcium current and release measured in squid presynaptic terminal (Augustine et al., 1985) and estimates of this relationship at crayfish neuromuscular junction (Dudel, 1981; Zucker and Lara-Estrella, 1983), how much of an increase in influx might be expected to 
account for the three- to fivefold enhancement of EJP amplitude produced by $5-\mathrm{HT}$ ? Transmitter release is estimated to relate to the third to fifth power of presynaptic calcium current in a variety of preparations, suggesting that an increase in calcium current of $32 \%$ for a fifth-order relationship and $60 \%$ for a thirdorder relationship would be required for fourfold enhancement. With a pre-5-HT accumulation of $300 \mathrm{nM}$ in $50 \% \mathrm{NVH}$, an increased accumulation ranging between $100 \mathrm{nM}$ (5th power) and $180 \mathrm{~nm}$ ( $3 \mathrm{rd}$ power) would be expected, which is well within our ability to detect if the increased calcium influx was linearly translated to an increased accumulation.

Calcium imaging measurements cannot fully substitute for voltage-clamp measurements of presynaptic calcium current because our present understanding of how an increased calcium accumulation measured during trains of action potential relates to calcium current is incomplete. Therefore, our experiments that increased influx to an extent sufficient to produce synaptic enhancement equivalent to that produced by 5-HT are important for providing evidence that a lack of an increase in accumulation in 5-HT reflected a lack of increased influx. Increasing action-potential-mediated calcium influx enough to increase EJPs two- to fivefold by increasing extracellular calcium or by TEAinduced spike broadening produces detectable changes in accumulation. It is unlikely, therefore, that 5-HT enhances transmitter release by broadening the action potential or by changing the voltage-dependent kinetics of presynaptic calcium channels.

Our observation that doubling the extracellular calcium concentration from 6.8 to $13.5 \mathrm{~mm}$ results in approximately fourfold enhancement of transmitter release but only a $30 \%$ increase in accumulation may indicate that calcium channels behave as if they are partially saturated at these concentrations as in other preparations (Hagiwara and Byerly, 1981; Kostyuk, 1989), but unlike squid presynaptic calcium channels (Augustine et al., 1985), or may reflect extracellular buffering of calcium within the synaptic cleft (Ginsburg and Rahamimoff, 1983). If the change in accumulation accurately reflects the magnitude of the change in presynaptic calcium current at release sites, then the relationship between calcium current and transmitter release in crayfish resembles a high-order power function as seen in squid (Augustine et al., 1985).

Some important caveats remain. First, 5-HT may, in addition to increasing the influx associated with each action potential, also alter the calcium removal systems so that the increased load is dealt with more efficiently, with the result that the accumulation remains essentially unchanged. Although effects of 5-HT on calcium removal rate were not carefully tested, we saw no obvious increases in the rate of recovery of calcium after short trains of action potentials. The fact that accumulations were in some experiments slightly less in response to actionpotential trains delivered during 5-HT application may indicate an enhanced removal of calcium. If so, then the enhancing effects of 5-HT on the transmitter-release machinery are actually greater than they first appear because they are acting to increase release in the face of reduced influx. However, it is more likely that they reflect a slightly reduced calcium influx associated with the 5-HT-mediated reduction in action-potential amplitude (Dixon and Atwood, 1985).

Second, though increasing the extracellular calcium concentration increases release and produces an increased accumulation of calcium during a train of action potentials, could a slight increase in the number of calcium channels opening, rather than the calcium flux per channel, have a large effect on amount of transmitter relcascd relative to the accumulation of calcium during the train and so remain undetected by our measurements of calcium accumulation? To approach this question, one must consider the possible relationships between microdistribution of calcium channels and release sites (Simon and Llinas, 1985; Zucker and Fogelson, 1986). In the extreme case, where there is no overlap between calcium domains associated with the individual channels that contribute to the release of vesicles (i.e., no cooperativity between channels), doubling the number of open channels, for example, by prolonging the action potential, would double the number of vesicles released. In this situation, doubling the number of channels will double the influx of calcium and thus greatly increase the calcium accumulation relative to the enhancement of the EJP. If instead release was normally driven by calcium concentrations resulting from the overlap, and therefore the summation of calcium, from several channel domains, then increasing the number of channcls opcn would be expected to increase release greatly for a small increase in total calcium influx. Broadening the spike increases the number of calcium channels that will open during the action potential and probably increases the number of channels open before repolarization begins. Nonextensive overlap between calcium domains contributing to release is therefore suggested by our observation that the change in calcium accumulation is related to the change in release by a power between 1 and 2 when the spike is broadened with TEA. This suggests that, for 5-HT to produce fourfold enhancement of evoked transmitter release by increasing the number of channels open during an action potential, a large enough number would have to be opened to produce appreciable increases in accumulation.

Recently, Bley et al. (1990) have reported that noradrenaline shifts the probability that $\mathrm{N}$-type calcium channels will exist in one of two states during depolarization: a long-opening lowconductance state versus a short-opening high-conductance state. It is conceivable that such a shift in channel kinetics and conductance could result in little change in the total calcium current evoked by an action potential (therefore the calcium load and calcium accumulation in the cytoplasm) while producing higher local concentrations near channel mouths and greater release as a result of a higher but shorter conductance. If such an effect were produced by 5 -HT in our experiments, it would not be detected by our fura- 2 measurements of accumulation. However, the fact that 5-HT increases the frequency of spontaneous release of transmitter quanta suggests that an undetected change in the detailed characteristics of calcium current during an action potential is not responsible for 5-HT-induced enhancement of evoked transmission.

Finally, the large increase in calcium accumulation relative to enhancement of the EJP seen with TEA application is correlated with an increased rate and magnitude of frequency-dependent facilitation during tetanic stimulation (Wojtowicz, 1990; present results). Because neither of these effects is seen with 5-HT application, it is unlikely that $5-\mathrm{HT}$ acts by broadening the presynaptic action potential.

\section{5-HT directly activates the release mechanism or increases its sensitivity to calcium}

Because of the lack of effect of 5-HT on resting calcium concentrations or action-potential-mediated calcium influx, we favor the hypothesis that 5-HT acts to increase the effectiveness of calcium for stimulating release of transmitter, rather than changing the concentration of calcium at release sites following 
an action potential. This study and others (Glusman and Kravitz, 1982; Niles and Smith, 1982) indicate that, to a first approximation, enhancement of release by 5 -HT remains the same despite large differences in concentration of intracellular calcium driving release or in the rate of release. That is, action-potentialevoked release is enhanced by approximately the same amount as spontaneous release despite being driven by calcium concentrations presumably 100 times greater than the resting calcium concentrations present during spontaneous release. Furthermore, we found that HiOsm saline increases mFJP frequency two- to sixfold while approximately doubling $\left[\mathrm{Ca}^{2+}\right]_{i}$, and that $5 \mu \mathrm{M}$ 5-HT further elevates this spontaneous release rate 2-10fold without changing $\left[\mathrm{Ca}^{2+}\right]_{i} .5-\mathrm{HT}$ enhances the evoked EJP amplitude in HiOsm saline approximately fivefold. Reducing the extracellular calcium concentration from 13.5 to 6.75 or 4.2 mM reduces the evoked EJP approximately four- or ninefold, respectively, yet 5-HT enhances the EJP in reduced-calcium $\mathrm{NVH}$ to the same extent as in NVH (present results; see also Dudel, 1988). Finally, tetanically facilitated release during trains of stimuli (in normal or reduced-calcium NVH), which is associated with increases in residual calcium of between 100 and $500 \mathrm{nM}$, depending upon the rate of stimulation, is enhanced by 5 -HT to the same extent as unfacilitated low-frequency relcasc. Therefore, biochemical models for the action of 5-IIT must accommodate multiplicatively constant effects of 5-HT that are largely independent of the absolute rate of release or the concentration of calcium associated with release.

Effects on the transmitter release mechanism, rather than on calcium current or resting calcium concentration, have recently been proposed to explain part of the effects of 5-HT and FMRFamide at cultured molluscan synapses (Man-Son-Hing et al., 1989; Dale and Kandel, 1990). Pieroni and Byrne (1989) have shown that 5-HT enhances transmission at Aplysia sensory to motor synapses independent of an effect on spike broadening and consistant with an increased "mobilization" of transmitter. Gingrich et al. (1988) propose that in Aplysia sensory neurons 5-HT serves to relieve synaptic depression by increasing the availability of quanta for release. Depression is not readily observed at crayfish opener neuromuscular junction even with high-frcqucncy stimulation. Release probabilities are low in the absence of facilitation or potentiation, and repetitive stimulation readily elevates and maintains release $10-100$-fold within seconds, suggesting that initially low release probability is not a result of a shortage of vesicles per se, but rather may reflect a shortage of competent sites at which fusion of synaptic vesicles and the presynaptic membrane can occur. Alternatively, there may be a large supply of vesicles within the immediate vicinity of release sites, but the number that are competent to bind to release sites within a fraction of a millisecond of the actionpotential-mediated calcium influx may be increased by $5-\mathrm{HT}$, perhaps by removal of an inhibitory vesicle-surface protein or freeing of vesicles from cytoskeletal elements in a manner similar to the proposed effects of phosphorylation of the vesicleassociated protein synapsin I (Llinas et al., 1985).

\section{References}

Adler EM, Augustine GJ, Duffy SN, Charlton MP (1988) Modulation of neurotransmitter release by intracellular calcium chelators at the squid giant synapse. Soc Neurosci Abstr 14:69.

Augustine GJ, Charlton MP (1986) Calcium dependence of presynaptic calcium current and postsynaptic response at the squid giant synapse. J Physiol (Lond) 381:619-640.
Augustine GJ, Charlton MP, Smith SJ (1985) Calcium entry and transmitter release at voltage-clamped nerve terminals of squid. J Physiol (Lond) 369:163-181.

Barton SB, Cohen IS, Van der Kloot W (1983) The calcium dependence of spontaneous and evoked quantal release at the frog neuromuscular junction. J Physiol (Lond) 337:735-751.

Bley KR, Lipscombe D, T'sien RW (1990) Neurotransmitter modulation of N-type Ca channels by shifts between modes of gating. Soc Neurosci Abstr 16:612.

Charlton MP, Smith SJ, Zucker RS (1982) Role of presynaptic calcium ions in synaptic facilitation and depression at the squid giant synapse. I Physiol (Lond) 323:173-193.

Cohen IR, Van der Kloot W (1985) Calcium and transmitter release. Int Rev Neurobiol 27:299-336.

Dale N, Kandel ER (1990) Facilitatory and inhibitory transmitters modulate spontaneous transmitter release at cultured Aplysia sensorimotor synapses. J Physiol (Lond) 421:203-222.

Delaney KR, Zucker RS (1990) Calcium released by photolysis of DMnitrophen stimulates transmitter release at squid giant synapse. $\mathrm{J}$ Physiol (Lond) 426:473-498.

Delaney KK, Lucker RS, Tank DW (1989) Calcium in motor nerve terminals associated with posttetanic potentiation. J Neurosci 9:35583567.

Delaney KR, Llinas RR, Tank DW (1990) A component of facilitation at crayfish neuromuscular junction is linearly related to cytoplasmic calcium. Soc Neurosci Abstr 16:504

Dixon D, Atwood HL (1985) Crayfish motor nerve terminal's response to serotonin examined by intracellular microelectrode. J Neurobiol 16:409-432.

Dixon D, Atwood HL (1989a) Phosphoinositol system's role serotonin facilitation at the crayfish neuromuscular junction. J Neurophysiol 62:239-246.

Dixon D, Atwood HL (1989b) Conjoint action of phosphoinositol and adenylate cyclase systems in serotonin-induced facilitation at the crayfish neuromuscular junction. J Neurophysiol 62:1251-1259.

Dudel J (1965) Facilitatory effects of 5-hydroxy-tryptamine on the crayfish neuromuscular junction. Naunyn Schmiedebergs Arch Exp. Pathol Pharmacol 249:515-528.

Dudel J (1981) The effect of reduced calcium on quantal unit current and release at the crayfish neuromuscular junction. Pfluegers Arch $391: 35-40$.

Dudel J (1988) Modulation of quantal synaptic release by serotonin and forskolin in crayfish motor nerve terminals. In: NATO ASI Series, Vol H19, Modulation of synaptic transmission and plasticity in nervous systems (Hertting G, Spatz HC, eds), pp 259-270. Berlin: Springer.

Dutar P, Nicoll RA (1988) Stimulation of phosphoinositol (PI) turnover may mediate the muscarinic suppression of M-current in hippocampal pyramidal cells. Neurosci Lett 85:89-94.

Enyeart J (1981) Cyclic AMP, 5HT and the modulation of transmitter release at the crayfish neuromuscular junction. J Neurobiol 12:505513.

Fischer L, Florey E (1983) Modulation of synaptic transmission and excitation-contraction coupling in the opener muscle of the crayfish Astacus leptodactylus by 5-hydroxytryptamine and octopamine. J Exp Biol 102:187-198.

Gingrich KJ, Baxter DA, Byrne JH (1988) Mathematical model of cellular mechanisms contributing to presynaptic facilitation. Br Res Bull 21:513-520.

Ginsberg S, Rahamimoff $F$ (1983) Is extracellular calcium buffering involved in regulation of transmitter release at the neuromuscular junction? Nature 306:62-64.

Glusman S, Kravitz EA (1982) The action of serotonin on excitatory nerve terminals in lobster nerve-muscle preparation. J Physiol (Lond) 325:223-241.

Goy M, Kravitz EA (1989) cAMP accounts for some but not all of the effects of serotonin at lobster neuromuscular junction. $J$ Neurosci 9:369-379.

Grynkiewicz G, Poenie M, Tsien RY (1985) A new generation of $\mathrm{Ca}^{2+}$ indicators with greatly improved fluorescence properties. J Biol Chem 260:3440-3450.

Hagiwara S, Byerly L (1981) Calcium channel. Annu Rev Neurosci 4:69-125.

Harris-Warrick R, Kravitz EA (1984) Cellular mechanisms for mod- 
ulation of posture by octopamine and serotonin in the lobster. J Neurosci 4:1976-1993.

Huank K-P (1989) The mechanism of protein kinase C activation. Trends Ncurosci 12:425-432.

Hubbard JI, Jones SF, Landau EM (1968) An examination of the effects of osmotic pressure changes upon transmitter release from mammalian motor nerve terminals. J Physiol (Lond) 197:639-659.

Jahromi SS, Atwood HL (1974) Three-dimensional ultrastructure of the crayfish neuromuscular apparatus. J Cell Biol 63:599-613.

Kaczmarek LK, Levitan IB (1987) Modulation: the biochemical control of neuronal excitability. New York: Oxford UP.

Kao JP, Tsien RY (1988) Calcium binding kinetics of fura- 2 and azo-1 from temperature-jump relaxation measurements. Biophys J 53:635639.

Kita H, Van der Kloot W (1977) Time course and magnitude of effects of changes in tonicity on acetylcholine release at frog neuromuscular junction. J Neurophysiol 40:212-224.

Klcin M, Kandel ER (1978) Presynaptic modulation of voltagc-dependent $\mathrm{Ca}^{++}$current: mechanism for behavioral sensitization in Aplysia californica. Proc Natl Acad Sci USA 75:3512-3516.

Knight DE, von Grafenstein H, Athayde CM (1989) Calcium-dependent and calcium independent exocytosis. Trends Neurosci 12:452458.

Kostyuk PG (1989) Diversity of calcium ion channels in cellular membranes. Neuroscience 28:253-261.

Lando L, Giovannini J, Zucker RS (1986) Cobalt blocks the decrease in MEPSP frequency on depolarization in calcium-free hypertonic media. J Neurobiol 17:707-712.

Llinas RR, Steinberg IZ, Walton K (1981) Relationship between presynaptic calcium current and postsynaptic potential in squid giant synapse. Biophys $\mathbf{J}$ 33:323-351.

Llinas RR, McGuiness TL, Lconard CS, Sugimori M, Greengard P (1985) Intraterminal injection of synapsin I or calcium calmodulindependent protein kinase II alters neurotransmitter release at the squid giant synapse. Proc Natl Acad Sci USA 82:3035-3039.

Llinas RR, Sugimori M, Walton K (1987) Further studies on depolarization release coupling at squid giant synapse. Adv Exp Med Biol 221:1-17.

Man-Son-Hing H, Zoran MJ, Lukowiak K, Haydon PG (1989) A neuromodulator of synaptic transmission acts on the secretory apparatus as well as on ion channels. Nature 341:237-239.

Miledi R (1973) Transmitter release induced by injection of calcium ions into nerve terminals. Proc R Soc Lond [Biol] 212:197-211.

Niles WD, Smith DO (1982) Effects of hypertonic solutions on quantal transmitter release at the crayfish neuromuscular junction. J Physiol (Lond) 329:185-202.
Pethig R, Kuhn M, Payne R, Adler E, Chen T-H, Jafe LF (1989) On the dissociation constants of BAPTA-type calcium buffers. Cell Calcium 10:491-498.

Pieroni JP, Byrne JH (1989) Differential effects of serotonin $\mathrm{SCP}_{\mathrm{B}}$ and FMRFamide on processes contributing to presynaptic facilitation in sensory neurons of Aplysia. Soc Neurosci Abstr 15:1284.

Poenie M, Alderton J, Steinhardt R, Tsien R (1986) Calcium rises abruptly and briefly throughout the cell at the onset of anaphase. Science 233:886-889.

Scholz KP, Cleary LJ, Byrne JH (1988) Inositol 1,4,5-trisphosphate alters bursting pacemaker activity in Aplysia neurons: voltage-clamp analysis of effects on calcium currents. J Neurophysiol 60:86-104.

Simon S, Llinas RR (1985) Compartmentalization of the submembrane calcium activity during calcium influx and its significance in transmitter release. Biophys J 48:485-498.

Smith SJ, Osses LR, Augustine GJ (1988) Fura-2 imaging of localized calcium accumulation within squid 'giant' presynaptic terminal. In: Ion channcl modulation (Grinnell A, Armstrong D, Jackson M, eds), pp 147-155. New York: Plenum.

Thompson S, Coombs J (1988) Spatial distribution of $\mathrm{Ca}^{2+}$ currents in molluscan neuron cell bodies and regional differences in the strength of inactivation. J Neurosci 8:1929-1939.

Van der Kloot W, Kita H (1974) The quantal release of transmitters at two neuromuscular junctions in the crayfish. Effects of hypertonic solutions, ANS, ethanol and X-537A. J Comp Physiol 91:111-125.

Wojtowicz JM, Atwood HL (1984) Presynaptic membrane potential and transmitter release at the crayfish neuromuscular junction. J Neurophysiol 52:99-113.

Wojtowicz JM, Atwood HL (1991) Role of calcium-dependent potassium conductance in transmitter release at the crayfish neuromuscular synapse. Neuroscience, in press.

Zucker RS (1974) Crayfish ncuromuscular facilitation activated by constant presynaptic action potentials and depolarizing pulses. J Physiol (Lond) 241:69-80.

Zucker RS, Fogelson AL (1986) Relationship between transmitter release and presynaptic calcium influx when calcium enters through discrete channels. Proc Natl Acad Sci USA 83:3032--3036.

Zucker RS, Haydon PG (1988) Membrane potential plays no direct role in evoking neurotransmitter release. Nature 335:360-362.

Zucker RS, Lara-Estrella LO (1983) Post-tetanic decay of evoked and spontaneous transmitter release and a residual-calcium model of synaptic facilitation at crayfish neuromuscular junctions. J Gen Physiol $81: 355-372$ 